\title{
English Language Teaching Methods in Uganda: From Past to Present
}

\author{
Shira Tendo Namagero* \\ Senior Lecturer, School of Education, Mountains of the Moon University, Fort Portal, Uganda.
}

*Corresponding Author: Shira Tendo Namagero, Senior Lecturer, School of Education, Mountains of the Moon University, Fort Portal, Uganda.

\begin{abstract}
This study was a response to numerous complaints in the media about students' inability to communicate effectively in English which was blamed on ineffective teachers of English language. A historical review of the teaching methods which have been used in Uganda from colonial times to present date is presented below. Using qualitative research methods of observation, interviews, questionnaires and review of related literature, data was collected on the methods teachers were using and had used to teach English language in Uganda overtime. The research was conducted among retired English language teachers $(R T)$ and practicing teachers $(P T)$. Conclusions were made for policy makers on teacher teaching programs and teaching methods.
\end{abstract}

Key terms: Teaching methods, Grammar translation or traditional method, The Direct Method, The Reading Method, The Audio lingual Method, The Audiovisual Method, Communicative Method

List of Abbreviations: RT: Retired Teachers, PT: Practicing Teachers, GT: Grammar Translation method, DT: Direct Method, RM: Reading method, AL: Audio Lingual method, AV: Audio Visual method, CM: Communicative method

\section{INTRODUCTION}

According to (Wikipedia, 2020) a teaching method refers to the principles and methods used by teachers to enable student learning. A teaching method can also be defined as a particular technique that the teacher uses to conduct a lesson. The methods discussed in this study include: grammar translation, audio lingual method, audio visual method and the communicative approach. Over time, it has been observed that teachers have neglected good teaching methods which emphasize the four skills: reading, writing, listening and speaking. In March 2002 one of Uganda's honourable ministers Amanya Mushega lamented about the state of English in Uganda.

'Most rural schools no longer enforce speaking English at school as was the practice in the 1970s and 80s. ... Sometimes they even hold academic discussions in their local languages. ..... Flexibility in marking could be a solution but a change in the teaching method must certainly take place. In the 1960s debates were part of the English lessons. Today, debates are considered extra-curricular activities. (Mushega, 2002:1)

In the same newspaper there was an article by Mukholi. D and Mugeere. A,

In Uganda, the decline in English language performance in schools and general everyday use can be blamed on poor teaching methods and lack of literature. ... In most cases, vocabulary selection is poor, while the concept of reading is dead in most schools particularly in the countryside... ( Mukholi.D. , Mugeere,A., 2002:3)

According to the Sunday Vision $31^{\text {st }}$ March 2002,

The appearance of English on the decline slide is not surprising. Although able to list the main points in an essay, many students fail to support them because they lack the art of communication, which basically amounts to a language problem. (Mushega, 2002:1)

Last year another review was done on the learners ability to learn a certain number of words in English and it was discovered that, 
Learners need more time to be exposed to the language before they can learn through it. But children in government schools mostly use their mother tongues and aren't exposed to media in English. Moreover, teachers in rural areas are not very proficient in English. We conclude that Uganda needs to rethink how English is taught in rural contexts. (Ssentanda, 2019)

The methods of teaching English language in Uganda are diverse. Some teachers use only the old methods to teach while other teachers integrate a variety of teaching methods to achieve their goaldepending on the set goal for each lesson.

\section{Methodology}

A qualitative approach was employed and data was collected through in-depth interviews, questionnaires, observations, group discussions and document analysis. Random sampling was used to select the schools for the study. Data was analyzed using qualitative methods and employed the following analysis tools: - identification of themes, coding of catalogues and assembling them, descriptive research design in order to draw conclusions and document analysis of lesson plans and classroom interactions between the teachers and their students. A cross sectional research design was used to observe subset of a population of teachers in which, groups (Retired Teachers (RT) and Practicing Teachers (PT)) were compared at different times with respect to independent variable: teaching methods.

\section{FINDINGS AND DISCUSSION}

\subsection{Methods of Language Teaching}

There have been various methods of teaching English language in Uganda: the direct method, grammar translation method, the reading method, the audio lingual method, the audio visual method and the communicative approach. The teaching of English language in Uganda was conducted using different methods in pre- independence time and post independence time. Each method has contributed to language learning in its own right. (Holden, 1996). The teaching of English has evolved over the years with newer methods being introduced and the older ones have either been integrated or discarded depending on the advantages they offered to both the teaching and learning communities.

\section{a) Grammar translation or traditional method}

This method was the offspring of German scholars whose objective was to know everything about something rather than the thing itself. (Richards J.C , T.S. Rodgers, 1998) According to Richards, grammar translation is a way of studying a language that approaches the language first through detailed analysis of its grammar rules, followed by application of this knowledge to the task of translating sentences and texts in and out of the target language. Reading and writing were the major focus. Speaking and listening came in as secondary. Vocabulary selection was based solely on the selected text and the translation was provided and the rules presented and illustrated.

The sentence was considered as the basic unit of teaching and language practice. Accuracy was emphasized and learners were expected to attain high standards in translation. Grammar was taught deductively by presentation and study of grammar rules, which they then practiced through translation exercises. The learners' native language was the medium of instruction and it was used to explain new items and comparisons between the two languages. The teaching materials used where mainly academic literature that had been written in the target language. Textbooks were prepared to teach 'modern languages' like English on similar lines to those of Latin and Greek.

This method was the first to be introduced in Uganda during the colonial era. It is still in use in Uganda in most, if not all schools outside the capital city. In the capital city it is limited or rarely used because of the many tribes that live in the city which make the choice of local language to translate into difficult. The teachers explained that it was the only way to get the learners to understand what was taught because most of them did not know enough English to follow the lesson in English. Learners and teachers in most rural schools translate whole chunks of speech from one language to another. The major defect of the grammar translation method lies in the overemphasis on the language as a mass of rules and in the limitations of practice techniques, which never emancipate the learner from the dominance of the first language. On top of that the sheer size of the task of memorization and the lack of coherence within the language make this method very limited. Most present day learners in Uganda who study under this method get to university when they are not able to hold a coherent conversation in English with someone without adding words from their mother tongues. 


\section{b) The Direct Method}

The method was first introduced in France and Germany and later was recognized officially by the governments of Germany, France and Belgium. An international congress of modern language teachers was held in 1898 in Vienna and decided that the direct method should be used in all elementary teaching of foreign languages (Rivers, 1972). In Britain a compromise policy of adopting the direct method's emphasis on the spoken language and some other techniques was recommended in the early 20th century. The direct method represents a shift from literary language to the spoken everyday language as the object of early instruction, a goal that was totally lacking in grammar translation. Classroom instruction was conducted exclusively in the target language (Harvey, 1936)

When this method was introduced in Uganda in the 1960s it was mainly practiced in the urban areas where students had interaction with white people and could relate what was taught to what they had heard an English native speaker say in their neighbourhood. It is still used in some schools especially the urban areas where the pupils come from homes with televisions and have exposure to English on a daily basis. This method was not embraced in rural areas which maintained grammar translation because their pupils did not have access to native English speakers either physically or on television.

Then the Direct Method was started as a result of many students failing to express themselves in English at that time, and this method encouraged the teaching of only sentences which are used in everyday communication. Oral communication skills were built up in a carefully graded progression organized around question and answer exchanges between teachers and students in small, intensive classes. Grammar was taught through demonstration, objects, pictures, and association of ideas with abstract vocabulary. In this method speech and listening comprehension, correct pronunciation and grammar were emphasized by the British teachers who conducted the English lessons at that time. This method is still used to some extent in the nursery schools where English is taught through objects, pictures and demonstrations.

According to (Whitehead, 1966) two major problems persistently troubled direct teaching method. One was how to convey meaning without translation and safeguarding against misunderstanding without reference to the first language. The other problem was how to apply the direct method beyond elementary stages of language learning. It was argued that because of the absence of translation, the method made it very difficult to convey the semantics or to teach grammar. The direct method could only be practiced in a classroom where the number of learners was limited because certain activities involved in the method were not easily applicable in a larger group of learners which was the case in most schools in Uganda whose classroom size ranged from 50 learners to over 100 learners. The main drawback was attributed to the difficulty in finding a native speaker to teach the foreign language and the method was far too dependent on the qualifications of the teacher rather than on the textbook. It was difficult to recreate the learning conditions of the native language in the foreign language classroom. Some of the learning conditions included size and materials used in the classrooms of the English native speakers. It was difficult to recreate scenes from the four seasons in England in the hot tropical Ugandan setting. This meant that all stories and dressings associated with winter like mittens were foreign to the English second language learners in Uganda and the learners did not have anything to relate the words to.

\section{c) The Reading Method}

In 1926 West, a British educator and later in 1953 Bond an American educator, advanced this method and they deliberately restricted the goals of language teaching to training in reading comprehension (Mackay, 1981) The reading method grew out of practical educational considerations of the 1920s and not from a shift in linguistic or psychological theory.

In Uganda, this method was not used exclusively but as a compliment to other methods. It was favoured by the urban schools which availed the learners a lot of reading materials outside of the syllabus content. Many urban schools in the 1980s had series of novels, short stories which they provided free to the learners according to their level. Presently it is used in urban schools but not with the same intensity as in the 1980s owing to the current over emphasis on grades at the end of the course. In the rural schools the teacher was lucky to even have a reference textbook for him/herself and it made this method impossible to implement there. However even where the reading method is used it is not used independently on its own. The RT who had used this method recommended it highly and most said that it was the reason why the reading culture had dropped among students. ( Mukholi.D. , Mugeere,A., 2002:3) 


\section{d) The Audio Lingual Method}

According to (Cochran.A.M., 1957) the theory of language underlying audiolingualism was derived from a view proposed by American linguists in the 1950s. This method views the learning process as one of habituation and conditioning without the intervention of any intellectual analysis. It lays emphasis on active and simple practice. It encourages the separation of the language skills: listening, speaking, reading, and writing and the primacy of the audio lingual over the graphic skills. Emphasis was placed on certain practice techniques, mimicry, memorization and pattern drills. It encourages the use of language laboratories. It established a linguistic and psychological theory as a basis for the teaching method and it was avowedly behavioristic.

According to the responses to the questionnaires, interviews and observations conducted among RT and PT, this method was not used in Uganda for teaching English language. The main reason was the lack of laboratory facilities to conduct those lessons. Even the teachers themselves were not very confident of their pronunciations of some words in the English language as a result of the influence of their mother tongues.

\section{e) The Audiovisual Method}

This method was developed in the 1950s in France by a team directed by Guberina and Rvenc. (Randolf Quirk, A.H.Smith, 1959) . Its main emphasis was a visually presented scenario were the learners were involved in meaningful utterances and contexts. Language learning was visualized as falling into several stages: the first stage where it was particularly applicable and the learners became familiar with everyday language. A second stage involved the capacity to talk more consecutively on general topics and to read non-specialized fiction and newspapers. The third stage involved the use of more specialized discourse of professional and other interesting topics. In contrast to the audiolingual method it stressed the social nature and situational embeddedness of language.

The difference between audio-lingual and audiovisual methods is minimal. Audio-lingual is talk and hearing while audiovisual is talk and see but you cannot talk and see without hearing that is why it is said that the difference is minimal.

The audio visual method was not adopted by the teachers in Uganda because of its rigidity in teaching sequences and difficulty in conveying meaning. The Integrated English textbooks (Nsibambi, 1995) encouraged this method but owing to financial constraints they failed to have it implemented.

\section{f) Communicative Method}

This method focused on language as a medium of communication and viewed all communication as having a social purpose - learners were encouraged to say something during the lesson. For example: seek information, express their likes and dislikes. This movement which flourished in 1970's and 80's - raised pupils' motivation through short-term objectives and through teaching language appropriate to a range of relevant topics and situations like: shopping, hobbies, and exchanges. In Uganda a group of scholars came up with the Integrated English textbook based on the communicative method which offered opportunities for communication to learners at different levels and during each lesson. (S.B.Akabway, C.R.M. Kiganda, P.W. Songa, R.J.Nsibambi, 1991)

This method was much more pupil-orientated, because it was dictated by pupils' needs and interests. The classroom was to provide opportunities for rehearsal of real-life situations and provide opportunity for real communication. Emphasis on creative role-plays, simulations, surveys projects, playlets, - all producd spontaneity and improvisation - not just repetition and drills. It placed emphasis on active modes of learning, including pair work and group-work.. It also emphasized oral and listening skills in the classroom and having personal contact with language, practice sounds, formulate sentence patterns and get a chance to make mistakes and learn from doing so.

This method was used selectively depending on the level of the learners and the teacher's educational background. Because classes which employed this method tended to be noisy, many teachers shied away from it. It did not place much emphasis on what most teachers considered necessary to pass examinations which were structured to examine reading and writing skills only. Teachers were encouraged to develop learning materials on the basis of particular needs manifested by the class which was not a fair expectation knowing that most teachers lacked textbooks especially in rural schools. This method did not put into consideration the linguistic variation of the teachers and learners. . 
Below is a graphic summary presentation of the usage of the different language teaching methods in Uganda compiled from the responses to the questionnaires, interviews and observations during classroom visitations.

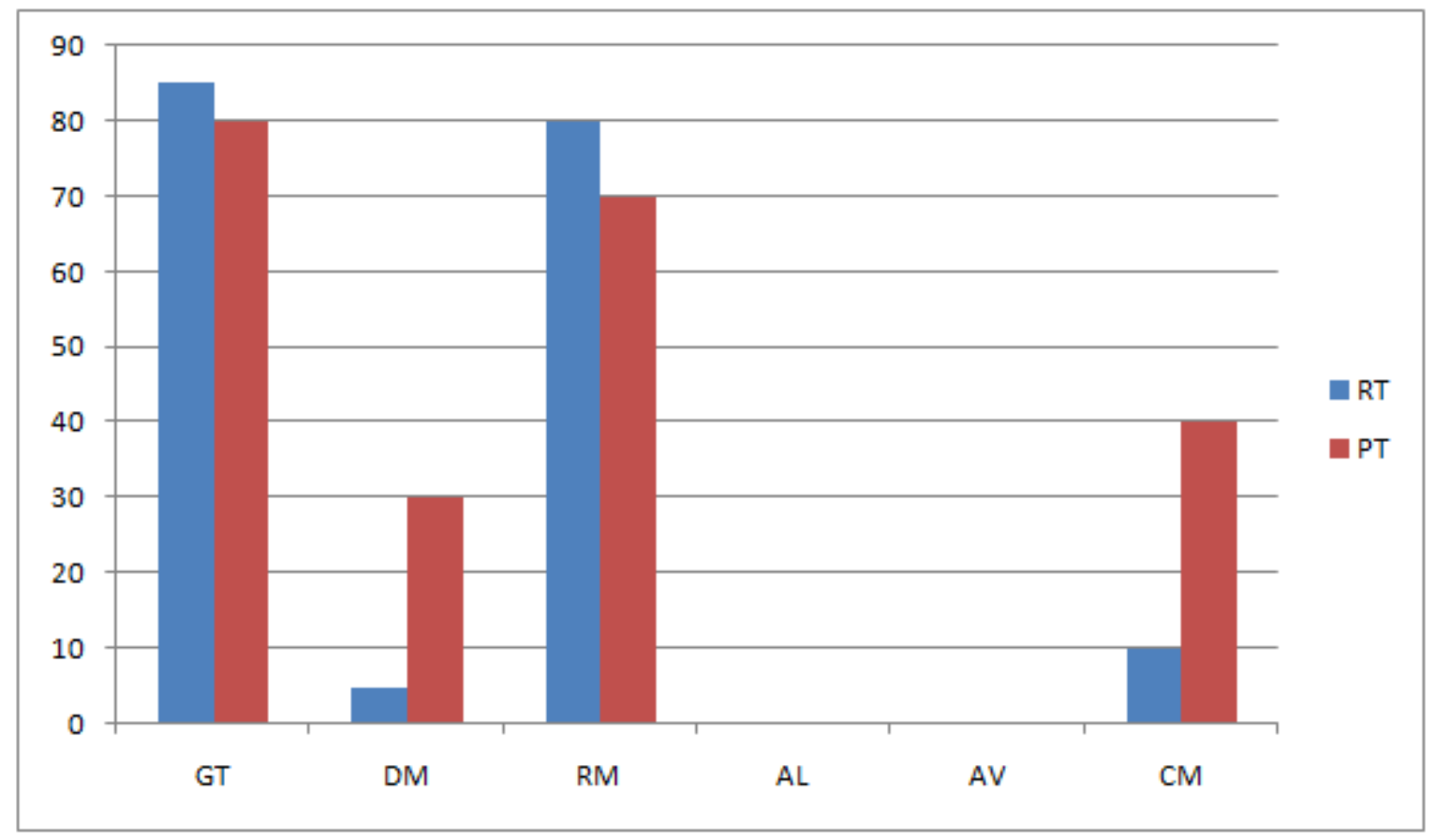

Figure1. PT and RT utilisation of language teaching methods in Uganda

KEY: RT Retired Teachers, PT Practicing Teachers, GT Grammar Translation method, DT Direct Method, RM Reading method, AL Audio Lingual method, AV Audio Visual method, CM Communicative method

\section{CONCLUSION}

The most used methods in teaching English language in Uganda were GM and RM. These two methods suited the Uganda National Examinations Board (UNEB) system which examined only the reading and writing skills. Many of the teachers viewed the communicative approach (which was the most effective teaching method in facilitating learner practice in the target language) as a waste of time because it required the teachers to teach all the four language skills. Even though a team of scholars had developed materials suited to the local context with local content. (S.B.Akabway, C.R.M. Kiganda, P.W. Songa, R.J.Nsibambi, 1991)

These is need by the Ministry of Education to work with (UNEB) to change the English language examination structure and include aspects of examining the speaking skill if the nation would like to see products of the education system who have a good command of the English language.

There is limited support in terms of textbooks especially in public schools. Most of the rural schools did not have textbooks and yet English language requires learners to have personal reading materials. The teachers both RT and PT felt that there was need for government funding in terms of textbooks for both teachers and learners. Some schools had only one textbook which meant that the teacher was forced to use methods like GM and DM.

\section{REFERENCES}

[1] Bryan M and Adelheid H. (2017). Routledge Encyclopedia of Language Teaching and Learning. London: Routledge.

[2] Freeman J and Freeman D. (1996). Teacher learning in language teaching. Cambridge: Cambridge University press.

[3] Mukholi.D. , Mugeere,A. (2002:3, March 31). State of English Language in Uganda. The Sunday Vision . Kampala: The New Vision Uganda.

[4] Afolayan AA and Newsum HE. (1986). The use of English, communicative skills for university students. Harlow: Longman Ltd. 
[5] Bailey KM and Nunan D. (1996). Voices from the Language classroom. Cambridge: Cambridge University Press.

[6] Brown G and Yule G. (1983). Teaching the spoken language. An approach based on the analysis of conversational English. Cambridge: Cambridge University Press.

[7] Brumfit, C. (1987). Literature and Language teaching. Oxford: Oxford University Press.

[8] Cochran.A.M. (1957). Modern methods of teaching English as a foreign language. Washington: Educational Services.

[9] Frisby.A.W. (1964). Teaching English. Notes and comments on teaching English Overseas. London: Longman.

[10] Gurrey, P. (1962). Teaching English grammar. London: Longman ltd.

[11] Harvey, W. (1936). English as a second language: a record of thirty years teaching. London: Oxford University Press.

[12] HASAN. R, HALLIDAY. M.A.K. (1989). Langauge, Context and Text: Aspects of Language in a SocialSemiotic Perspective,2nd.ed. Oxford: Oxford University Press.

[13] Holden, S. (1996). Techniques of Teaching, from theory to practice. London: Modern English publications ltd. .

[14] Mackay, W. F. (1981). Language Teaching Analysis. Harlow: Longman.

[15] Mushega, H. A. (2002:1, March 31st). The declining standards of English language in Uganda.

[16] Nsibambi, R. (1995, July 23). The Integrated Approach in Language teaching. Language Skills in National Curriculum Development. Dunford, Sheffield, England: Oxford University Press.

[17] Randolf Quirk, A.H.Smith. (1959). The teaching of English. London: Secker \& Warburg.

[18] Richard Hayes, Brittany Kyer, Emily Weber. (2015, December). The Case Study Cookbook. Retrieved 2020, from https://web.wpi.edu/Pubs: https://web.wpi.edu/Pubs/E-project/Available/E-project-121615164731/unrestricted/USPTO_CookbookFinal.pdf

[19] Richards J.C , T.S. Rodgers . (1998). Approaches and Methods in Language Teaching. Cambridge: Cambridge University Press.

[20] Rivers, W. (1972). Teaching Foreign Language Skills. Chicago: University of Chicago Press.

[21] S.B.Akabway, C.R.M. Kiganda, P.W. Songa, R.J.Nsibambi. (1991). Integrated English for Uganda: Students' Book 1- 4. Kampala: Macmillan Education.

[22] Ssentanda, M. (2019, November 04). Teaching English. Retrieved April 20, 2020, from The Independent Magazine: https://www.independent.co.ug/analysis-teaching-english/2/

[23] Stern, H. (1983). Fundamental concepts of Language Teaching. Oxford: Oxford University Press.

[24] Whitehead, F. (1966). The Disappearing Dias, A study of the principles and practices of English teaching. London: Chatto \& Windus.

[25] Wikipedia. (2020, April 02). Teaching method. Retrieved April 10, 2020, from Wikipedia, the free encyclopedia: https://en.wikipedia.org/wiki/Teaching_method

\section{AUTHOR'S BIOGRAPHIES}

Dr. Tendo, currently works as a Senior Lecturer with Mountains of the Moon University, Uganda. She has conducted a lot of qualitative research on teacher education, teaching techniques of English language to second language learners, the effectiveness of English language textbooks on the school syllabus over the years, Linguistics, the three genres of African literature, English literature, and American literature.

Citation: Shira Tendo Namagero. "English Language Teaching Methods in Uganda: From Past to Present" International Journal of Humanities Social Sciences and Education (IJHSSE), vol 7, no. 11, 2020, pp. 54-59. doi: https://doi.org/10.20431/2349-0381.0711007.

Copyright: (c) 2020 Authors. This is an open-access article distributed under the terms of the Creative Commons Attribution License, which permits unrestricted use, distribution, and reproduction in any medium, provided the original author and source are credited. 